\title{
Contra a Limpeza Étnica do Povo Palestino, MEMÓRIA E HISTÓRIA
}

\author{
Soraya Misleh de Matos $^{1}$
}

\begin{abstract}
Resumo:
Este artigo discorre sobre a história da Palestina como exemplo contemporâneo de construção ideológica que objetivou promover o memoricídio para fins de colonização e ocupação de terras. Autores mostram que houve um plano deliberado de limpeza étnica dos habitantes árabes nativos a partir de 1947 para a instituição de um estado homogêneo, exclusivamente judeu. A morte da memória dos palestinos encontrase na base do pensamento sionista, tanto que deu origem a mitos, como o de "uma terra sem povo para um povo sem terra" e de que os imigrantes fariam do deserto um pomar. Lideranças desse movimento declararam abertamente que sua expectativa era do esquecimento. Aí se consolidou a tentativa de memoricídio. Todavia, os palestinos se recusaram a ser apagados do mapa e continuam a resistir, como se observa na nova ofensiva a Gaza, Palestina ocupada. Uma das formas tem sido narrar os acontecimentos que compõem sua tragédia. A memória tem sido importante elemento para a reconstituição histórica, fundamental para a reparação da injustiça e sedimentação de um caminho livre de opressão, ocupação de terras, expulsão e humilhação.
\end{abstract}

Palavras-chave: memória, história, sionismo, limpeza étnica, palestinos, esquecimento.

\section{Abstract:}

This article aims to discourse about the Palestine's history as a contemporary example of ideological construction which aimed to promote the memoricide to purposes of colonization and land occupation. Authors demonstrate that there was a deliberated scheme of ethnic cleansing of the native Arabian habitants since 1947 to the establishment of an exclusively Jewish State. The Palestinians' memory's death is in the basis of the Zionist thought, so that will give origin to myths, as "a land without a people for a people without land" and as that the immigrants would make an orchard from the desert. Leaderships of these movements openly declared that their expectations were the forgetfulness. There was consolidated the memoricide. However, the Palestinians refuse themselves to be erased from the map and continue to resist, as seen in recent attacks on Gaza, Occupied Palestine. One of the ways has been to tell their tragedy. The memory has been being an important element to the historical construction, fundamental to the repair of the injustice and sedimentation of a way free from oppression, land occupation, expulsion and humiliation.

Keywords: memory, history, Zionism, ethnic cleaning, Palestinians, forgetfulness.

${ }^{1}$ Jornalista formada pela Universidade Metodista de São Paulo em 1993. Pós-graduada em Globalização e Cultura pela Fundação Escola de Sociologia e Política de São Paulo em 2007. Mestre em Língua,Literatura e Cultura Árabes pela USP (Universidade de São Paulo). E-mail: sorayamisleh@yahoo.com.br. 
Os velhos morrerão, os jovens esquecerão.

(David Ben-Gurion, premiê de Israel em 1948, ano da criação desse estado.)

Talvez me despojes da última polegada da minha terra

Talvez aprisiones minha juventude Talvez me roubes a herança de meus antepassados

Móveis... utensílios e jarras

Talvez queimes meus poemas e meus livros

Talvez atires meu corpo aos cães

Talvez levantes espantos de terror sobre nossa aldeia

Mas não me venderei

ó inimigo do sol

E até a última pulsação de minha veia

Resistirei

(Tawfic Zayyad, poeta palestino) ${ }^{2}$

\section{Introdução}

O mundo vivencia há séculos a limpeza étnica de povos diversos com vistas à colonização de territórios. Indígenas, armênios, africanos, entre outros, enfrentaram esse processo, que abrange a prática de memoricídio, cujo objetivo é a morte da memória dos nativos. Este artigo se concentra em um caso contemporâneo, em andamento ainda em pleno século XXI: o dos palestinos. A diferença nesse caso é que o objetivo foi criar não um estado nacional burguês como os demais, mas exclusivamente judeu. Para tanto, o memoricídio pretendido valeu-se de representações bíblicas para afirmar vínculo com a Palestina dos habitantes que seriam transferidos para lá. No esforço por criar uma identidade nacional que sustentasse a ideia de "regresso" dessas pessoas de diferentes destinos àquela terra, deu-se o que Shlomo Sand chama de "invenção do povo judeu"3. Enfrentando há mais de 60 anos um plano deliberado de limpeza étnica, como apontam novos historiadores israelenses do porte de Ilan Pappé4, os palestinos jogam luz sobre a questão da memória e esquecimento.

A primeira é importante elemento à reconstituição histórica, conforme vários autores, em contraposição ao apagamento, uma ameaça e a possibilidade de consolidação do projeto colonialista. No caso palestino, o sionismo - movimento político

\footnotetext{
2 ZAYYAD, Tawfic. Trecho do poema de sua autoria "Discurso no mercado do desemprego".

${ }^{3}$ SAND, Shlomo. A invenção do povo judeu. Trad. Eveline Bouteiller, São Paulo: Editora Benvira, 2010.

4 PAPPE, Ilan. La limpieza étnica de Palestina. Trad. Luis Noriega, Barcelona: Memória Crítica, 2008.
} 
inaugurado em fins do século XIX na Europa central - atuou intensamente no sentido de garantir esse esquecimento por parte do mundo, de modo a consolidar seu projeto de estabelecimento de um estado exclusivamente judeu na Palestina. Assim, criou mitos como o de "uma terra sem povo para um povo sem terra" e de que os imigrantes que chegassem fariam florescer o deserto. Como mostra nova linhagem de historiadores israelenses, as lideranças sionistas sabiam desde sempre que aquela região era habitada por uma maioria árabe. Daí, a limpeza étnica seria o objetivo, para mudar a realidade local. Sob essa lógica, em 1948 - como consequência da criação do Estado de Israel (a nakba, catástrofe, para os palestinos) em 15 de maio daquele ano - cerca de 800 mil palestinos foram expulsos de perto de 500 aldeias, as quais foram destruídas. Seus nomes e características foram alterados. No lugar de algumas, como o vilarejo de Qaqun ${ }^{5}$, onde nasceu meu pai, Abder Raouf Ibrahim Yousuf Misleh, foram constituídos assentamentos no então recém-criado Estado de Israel e um parque nacional, em substituição às casas, mesquita, escola, plantações. Nenhum rastro de que ali havia uma aldeia de 2 mil habitantes. A serviço dessa política, o discurso orientalista, denunciado por Edward Said 6 .

A mudar o curso dessa história rumo ao esquecimento, a resistência dessa população, sob diversas formas, inclusive na preservação de sua cultura e identidade. Hoje, há, segundo dados da UNRWA (agência das Nações Unidas de assistência aos refugiados palestinos), cerca de 5 milhões de palestinos vivendo em campos de refugiados há um raio de $150 \mathrm{~km}$ de distância dos territórios palestinos ocupados por Israel. Além deles, ao redor do mundo mais alguns milhares, somando-se em torno de 10 milhões ao todo. Essas pessoas têm sido - ao lado dos milhares de palestinos que vivem sob ocupação militar e no que hoje é o Estado de Israel - uma fonte rica de memória. A esperança é de que tais testemunhos contribuam ao reconhecimento histórico da limpeza étnica e da tragédia palestina - ainda em curso, como se observa neste momento, diante da nova ofensiva à faixa de Gaza por Israel, a mais agressiva desde final de 2008 e começo de 2009. O reconhecimento histórico é crucial para se sedimentar caminho rumo a uma justiça plena, que culmine em uma Palestina livre, laica, democrática, sem racismo.

\footnotetext{
${ }^{5}$ Citado em PAPPE, Ilan, op. cit., pp. 183, 202 e 212.

${ }^{6}$ SAID, Edward. Orientalismo - O Oriente como invenção do Ocidente. Trad. Rosaura Eichenberg, São Paulo: Companhia das Letras, 2007, pp. 62 e 63.
} 


\section{Apagamento de rastros}

Um esforço para homogeneizar um país etnicamente heterogêneo mediante a expulsão de pessoas, sua conversão em refugiados e a destruição de lugares. Massacres servem para amedrontar os habitantes de modo que os sobreviventes e os que vivem nas proximidades abandonem suas casas. 0 próximo passo é eliminá-los da história oficial e popular do país e extirpá-los da memória coletiva. A conceituação é usada para definir limpeza étnica. É o que ocorreu na Palestina em 1948, ano da criação unilateral naquelas terras do Estado de Israel. ${ }^{7}$ A partir da aprovação pela Assembleia Geral das Nações Unidas da Resolução 181 em 29 de novembro de 1947, que recomendou a partilha da Palestina - então sob mandato britânico - em um estado judeu e um árabe, sem consulta aos habitantes locais, abriu-se caminho para a execução do plano de limpeza étnica pelo movimento sionista. Este se iniciou em fins do século XIX na Europa central e pregava a instituição de um estado exclusivamente judeu. Como afirma Pappe:

\footnotetext{
Para realizar seu projeto, os pensadores sionistas reclamavam o território bíblico, que recriavam (de fato, reinventavam) como o berço de seu movimento nacionalista. Desde seu ponto de vista, a Palestina estava ocupada por "forasteiros". ${ }^{8}$ (tradução nossa)
}

A busca era por assegurar esquecimento mediante o apagamento de rastros. ${ }^{9}$

\section{Orientalismo}

Nesse ponto, parece importante conhecer mesmo que brevemente o pensamento orientalista, que vai servir ao apagamento de rastros. Como constata Said, o argumento é de que "há ocidentais e há orientais. Os primeiros dominam; os últimos devem ser

\footnotetext{
7 PAPPE, Ilan, op. cit., p. 22.

8 Ibidem, p. 32.

9 RICOEUR, Paul. A memória, a história, o esquecimento. São Paulo: Editora Unicamp. Capítulo 3 - O esquecimento. Trad. Alain François, et al. São Paulo: Editora Unicamp, 2007.
} 
dominados, o que geralmente significa ter suas terras ocupadas, seus assuntos internos rigidamente controlados" 10 .

Esse estilo de pensamento refletia a atitude comum dos europeus em relação à Palestina já no século XIX. A população indígena deveria ser modernizada para seu próprio bem ou dar lugar aos recém-chegados e às suas ideias - entre os mais ambiciosos e enérgicos estariam os sionistas (PAPPE, 2007: 61).

Conforme o historiador israelense, viajantes, missionários e escritores europeus publicaram mais de 3 mil livros e relatos de viagem sobre a Palestina durante aquele século, todos eles pintando-a como um local primitivo, à espera de redenção por parte desses estrangeiros. Os primeiros sionistas chegaram à Palestina simultaneamente aos missionários, no século XIX. Como estratégia para convencer os judeus a imigrarem pois não havia esse ímpeto num primeiro momento -, procuravam reinventar a noção de regresso. Assim:

para muitos sionistas, a Palestina nem sequer era um território "ocupado" quando começaram a trasladar-se para lá em 1882, senão uma terra "vazia": os palestinos nativos que viviam no local lhes resultavam em grande medida invisiveis ou, caso contrário, pareciam-lhes uma dificuldade natural que haviam de conquistar e eliminar ${ }^{11}$. (tradução nossa)

Assim, criava-se o mito da "terra sem povo para um povo sem terra" - slogan cunhado por Israel Zangwill (1864-1926), um dos pioneiros do movimento sionista na Grã-Bretanha e proeminente escritor. (MASALHA, 1992: 6) 0 palestino, conforme a concepção orientalista, era transformado num não povo. Somente tamanha desumanização poderia conceber a limpeza étnica planejada e levada a cabo em 1948, que culminou na expulsão de cerca de 800 mil desses habitantes nativos e na destruição de perto de 500 aldeias (PAPPE, 2007: 171 e 175), e a continuidade de uma política expansionista e segregacionista até os dias atuais, baseada no assentamento ilegal de judeus em terras ocupadas e na expulsão dos árabes desses locais.

\footnotetext{
10 SAID, Edward, op. cit., p. 68.

11 PAPPE, Ilan, op. cit.
} 


\section{Reinvenção dos lugares}

Os orientalistas tiveram papel fundamental também na reinvenção das aldeias destruídas durante a chamada nakba palestina. O processo de "limpeza", como já foi citado anteriormente, incluiu apagar quaisquer vestígios de sua existência anterior e reinventá-las sob outra forma, segundo Pappe, como antigos lugares hebreus ${ }^{12}$.

O historiador israelense revela no livro La limpieza étnica de Palestina que o espólio resultante da limpeza étnica promovida naquele território foi acompanhado da mudança de nomes dos vilarejos. 0 autor chega a utilizar o termo "memoricídio" para descrever esse trabalho, realizado com o auxílio de arqueólogos e especialistas em estudos bíblicos, "que se ofereceram voluntariamente para colaborar com um 'comitê de nomes' oficial cuja tarefa era hebraizar a geografia da Palestina"13. Como parte desse movimento, a língua hebraica também foi recriada. 0 objetivo, puramente ideológico, era desarabizar a região, mudar sua história e, assim, garantir o sucesso do projeto colonial. Na ótica de Said, "reconstruir uma língua oriental morta ou perdida significava, em última análise, reconstruir um Oriente morto ou esquecido"14. E preparar o terreno para o que viria a ser feito no local posteriormente.

Muitos dos vilarejos destruídos deram, assim, lugar a parques e bosques israelenses, numa negação sistemática da nakba ${ }^{15}$ e busca por fazer com que aquelas paisagens tivessem aparência europeia. A escolha por espécies não nativas a serem plantadas nesses locais encontraria essa justificativa (PAPPE, 2008: 300).

0 historiador israelense lembra que o Fundo Nacional Judeu exibe em seu site oficial ${ }^{16}$ esses lugares como atração turística. A organização é apresentada como responsável pelo florescimento do deserto e a aparência europeia da paisagem. "Com orgulho proclama que esses bosques e parques se levantam sobre 'zonas áridas e desérticas': 'os bosques e parques de Israel nem sempre estiveram ali. Os primeiros colonos judeus que chegaram ao país em fins do século XIX encontraram uma terra desolada'."17

\footnotetext{
12 Ibidem, p. 296.

13 Ibidem, p. 298; tradução nossa.

14 SAID, Edward, op. cit., p. 178.

15 PAPPE, Ilan, op. cit., p. 299.

16 Conferir em http://www.jnf.org. Acesso em 29/11/2011.

17 PAPPE, Ilan, op. cit., p. 302.
} 


\title{
Considerações finais
}

Para Paul Ricoeur, tem-se de um lado a experiência de erosão da memória, experiência do envelhecimento e aproximação da morte. De outro, "as pequenas felicidades do retorno, às vezes inopinado, de lembranças que acreditávamos perdidas para sempre"18. Segundo o autor, a memória é antídoto ao esquecimento destruidor. Ele afirma:

\begin{abstract}
Uma das razões para acreditar que o esquecimento por apagamento de rastros corticais não esgota o problema do esquecimento é que muitos esquecimentos se devem ao impedimento de ter acesso aos tesouros enterrados da memória. 0 reconhecimento frequentemente inopinado de uma imagem do passado tem assim constituído, até agora, a experiência princeps do retorno de um passado esquecido. ${ }^{19}$
\end{abstract}

Ahmad H. Sa'di e Lila Abu-Lughod (2007: 13) destacam:

Se a mais distintiva medida da memória social palestina é a produção sob constante ameaça de apagamento e na sombra de uma narrativa e força política que a silencia, uma das mais características qualidades [...] é sua orientação para o lugar. Para os palestinos, os lugares do passado pré-nakba e sua terra têm um peso extraordinário. Não são simples lugares da memória, mas símbolos de tudo que tem se perdido e sítios de saudade aos quais o retorno é barrado.

Os autores argumentam que essa concepção norteia a visão lírica e mesmo poética das aldeias até 1948, que domina as narrativas dos palestinos. Para Rochelle Davis (2011: 25), o significado da palavra "nostalgia" é muito próximo ao caso palestino. Ela ensina que o termo "é pseudogrego e foi cunhado em 1688 por um médico suíço, Johannes Hofer, para descrever 'a triste lua proveniente do desejo de retorno à terra natal'".

Recorrer à memória é um passo fundamental ao reconhecimento histórico das injustiças cometidas em relação aos palestinos e à interrupção desse processo. 0 que é necessário para se sedimentar o caminho rumo à justiça plena, que inclui transformar o "desejo de retorno à terra natal" em realidade, direito inalienável e inegociável dos milhares de palestinos expulsos de suas casas.

\footnotetext{
18 RICOEUR, Paul, op. cit., p. 22.
}

19 Ibidem. 


\section{Referências bibliográficas}

DAVIS, Rochelle A. Palestinian Village Histories - Geographies of the Displaced. Califórnia: Stanford University Press, 2011.

HERZL, Theodor. O Estado judeu. Trad. David José Pérez, Rio de Janeiro: Garamond, 1998.

PAPPE, Ilan. História da Palestina Moderna - uma terra, dois povos. Trad. Ana Saldanha, Lisboa: Ed. Caminho, Lisboa, 2007.

La limpieza étnica de Palestina. Trad. Luis Noriega, Barcelona: Memória Crítica, 2008.

SA'DI, Ahmad; ABU-LUGHOD, Lila (eds). Nakba: Palestine, 1948, and the Claims of Memory. New York: Columbia University Press, 2007

SAND, Shlomo. A invenção do povo judeu. Trad. Eveline Bouteiller, São Paulo: Editora Benvira, 2010.

SAID, Edward. Orientalismo - O Oriente como invenção do Ocidente. Trad. Rosaura Eichenberg, São Paulo: Companhia das Letras, 2007.

MASALHA, Nur. Expulsion of the Palestinians: The Concept of "Transfer" in Zionist Political Thought, 1882-1948. Washington: Institute for Palestine Studies, 1992.

MISLEH, Abder Raouf Ibrahim Yusuf. Saudades da terra natal. Entrevista concedida a HARTMANN, Arturo; MISLEH, Soraya. Maio/2008, São Paulo. Disponível em http://www.icarabe.org.br/entrevistas/saudades-da-terra-natal. Acesso em $29 / 11 / 2011$.

RICOEUR, Paul. A memória, a história e o esquecimento. Capítulo 3 - O esquecimento. Trad. Alain François, et al. São Paulo: Editora Unicamp, 2007. 